\title{
Application of Modified Bentonites for Arsenite (III) Removal from Drinking Water
}

\author{
Dóra Buzetzky, Noémi Csilla Tóth², Noémi M. Nagy, József Kónya \\ 1 Lajos Imre Isotope Laboratory, Department of Physical Chemistry, Institute of Chemistry, Faculty of Science and Technology, \\ University of Debrecen, H-4032 Debrecen, Egyetem tér 1, Hungary \\ 2 Agilent Atomic Spectroscopy Partner Laboratory, Department of Inorganic and Analytical Chemistry, Institute of Chemistry, \\ Faculty of Science and Technology, University of Debrecen, H-4032 Debrecen, Egyetem tér 1, Hungary \\ * Corresponding author, e-mail: dorabeata@science.unideb.hu
}

Received: 08 March 2018, Accepted: 19 July 2018, Published online: 07 August 2018

\begin{abstract}
Four modified bentonites (La(III), Ce(III), Y(III), Fe(III)) were prepared by ion exchange process to remove arsenite (III) ions from water. The modified bentonites were examined with X-ray fluorescence spectroscopy (XRF) and X-ray diffraction (XRD). The rare earth (REE) and $\mathrm{Fe}(\mathrm{III})$ ion content in bentonite was higher than the CEC values obtained by ammonium acetate method related to trivalent ions $\left(2.7 \times 10^{-4} \mathrm{~mol} \mathrm{~g}^{-1}\right)$. The kinetics, equilibrium time, sorption isotherms and desorption experiments were examined. Lanthanum, yttrium and cerium bentonite can bind similar amount of arsenite(III) ions. Iron-bentonite cannot bind significant amounts of arsenite ions. The active sites and the solubilities of the sorption complex were determined. Arsenite (III) ions sorb in the interlayer space as $\mathrm{REEAsO}_{3}$. The solubility of the arsenite complex was two orders of magnitude smaller than that of the phosphate complex. After desorption the eluted amount of arsenite (III) was $55 \%$ related to the sorbed amount of arsenite. The $\mathrm{d}(001)$ basal spacing of modified bentonites and that of after sorption and desorption was measured. After the sorption of arsenite ion on lanthanum bentonite, the $d(001)$ basal spacing of montmorillonite was decreased and after desorption an increase in $\mathrm{d}(001)$ basal spacing was observed again. Modified bentonites can be used for removing arsenic ions from water.
\end{abstract}

Keywords

modified bentonite, arsenite (III), rare earth, groundwater, sorption experiments

\section{Introduction}

One of the most valuable substances on Earth is the clean water suitable for human consumption. The careless treatment and the poisoning of drinking water sources cause an enormous problem around the world.

Arsenic pollution of drinking water is a problem all over the world, mainly those developing countries are affected, where drinking water consist of especially groundwater [1]. Arsenic in water occurs due to anthropogenic effects, but generally it has geogenic origin [2]. In groundwater arsenic occurs as oxyanions; arsenite $\left(\mathrm{AsO}_{3}{ }^{3-}\right)$ and arsenate $\left(\mathrm{AsO}_{4}{ }^{3-}\right)$. The limit of arsenic concentration was reduced from $50 \mu \mathrm{g} / 1$ to $10 \mu \mathrm{g} / 1$ [3].

$\mathrm{As}(\mathrm{III})$ is more toxic than $\mathrm{As}(\mathrm{V})$, and As(III) is more difficult to remove from water than $\mathrm{As}(\mathrm{V})$ and generally occurs in water in large quantities. Arsenic can reach the human body by inhalation, ingestion or dermal absorption [4]. Epidemiological studies have presented that arsenic interact with some hormones in the human body and due to high arsenic concentration in drinking water the risk of bladder, lung, liver, skin and other cancers have increased $[2,5]$.

Several methods were determined to remove arsenic ions from drinking water, such as adsorption, oxidation, precipitation and ion exchange [6]. Nowadays several metal oxide adsorbents are spread to remove arsenic, for example activated bimetallic oxides [7-9] iron oxide [10-12] alumina [13-15], and other metal oxides [16, 17].

Clay minerals are used for adsorption of pollutants because they are cheap and ubiquitous in nature [18]. The main clay mineral of bentonite is montmorillonite, which is a good sorbent because it has high cation exchange capacity and a large specific surface area. Raw montmorillonite can sorb cations, but not anions, because of the negative charges on the crystal lattice. Therefore, several 
methods have been investigated in order to sorb anionic pollutants by montmorillonite $[19,20]$.

Our aim was to remove arsenic from water with modified bentonites, and to evaluate the As(III) sorption properties of modified bentonites. The kinetics, equilibrium time, sorption isotherms and desorption experiments were examined to determine the characteristic parameters. In this work, calcium bentonite surface was modified with lanthanum (III), yttrium (III), cerium (III), and iron (III) ions, because raw bentonite can sorb cations, but not anions, because of the negative charges on the crystal lattice. Modified bentonites are used for removing arsenite ions from water by adsorption or surface precipitation, a special way of sorption.

These four modified bentonites have been chosen because La-bentonite was used to remove the chemically similar phosphate anion. The idea was taken from the example of the lanthanum modified bentonite Phoslock, invented by CSIRO (Commonwealth Scientific and Industrial Research Institution) in Australia in the mid1990s. Phoslock decreases phosphate content in water bodies, preventing its re-release for use by algae [21]. $\mathrm{Ce}$ - and Y-bentonite are assumed to have similar properties to lanthanum bentonite but they are less expensive. The iron ions are ubiquitous in groundwater. For the application of these sorbents, their interfacial reactions must be known in aqueous media.

Our focus is on As(III) because it is more toxic than $\mathrm{As}(\mathrm{V})$, generally more likely to occur in water, and is more difficult to remove from water.

\section{Materials and methods}

\subsection{The characterization of calcium bentonite}

Rare earth (REE) bentonites were prepared from natural Ca-bentonite collected in Istenmezeje, Hungary. Elemental analysis of the original Ca-bentonite were measured with EDAX. It has the following composition: $73.29 \% \mathrm{SiO}_{2}, 18.71 \% \mathrm{Al}_{2} \mathrm{O}_{3}, 1.48 \% \mathrm{FeO}, 2.29 \% \mathrm{CaO}$ and $4.23 \% \mathrm{MgO}$ [22]. The X-ray diffraction and thermoanalytical results are: $71 \mathrm{~m} / \mathrm{m} \%$ montmorillonite, $12 \mathrm{~m} / \mathrm{m} \%$ cristobalite / opal CT, $8 \mathrm{~m} / \mathrm{m} \%$ illite, $4 \mathrm{~m} / \mathrm{m} \%$ quartz, $3 \mathrm{~m} / \mathrm{m} \%$ kaolinite, and $2 \mathrm{~m} / \mathrm{m} \%$ calcite. The cation exchange capacity (CEC) of Ca-bentonite was determined by ammonium acetate method [23] and it was $81 \mathrm{meqv} / 100 \mathrm{~g}$. The $\mathrm{d}(001)$ basal spacing of Ca-bentonite was 1.4769 .

\subsection{Preparation of trivalent cation exchanged (La, Ce, Y, Fe(III)) bentonites}

REE bentonites were prepared by an ion exchange process using calcium bentonite and rare earth solution. Ca-bentonite (20 g) was suspended in $\mathrm{REEClO}_{4}$ solutions $\left(4.7 \times 10^{-2} \mathrm{~mol} \mathrm{dm}^{-3}\right)$. REEClO 4 were prepared by dissolving REE oxides (purchased from Johnson, Matthey \& Co., pro anal.). The solutions were shaken for 5 hours, then centrifuged, washed, and dried at room temperature [22].

The preparation method of iron (III)-bentonite is different from the preparation of the rare earth bentonites due to the hydrolysis of iron (III) ions. To minimize the hydrolysis of cations, organic solvents may be applied. For example, iron (III)-montmorillonite can be prepared from acetoneous $\mathrm{FeCl}_{3}$ solution [25].

For the preparation of iron (III)-bentonite, $\mathrm{FeCl}_{3}(50 \mathrm{~g}$ ) was solved in acetone while cooling bath was used because of significant solvation heat. After the whole of $\mathrm{FeCl}_{3}$ was dissolved, a stoichiometric amount of calcium bentonite (based on calcium and iron (III) ions) was added to the $\mathrm{FeCl}_{3}$ dissolved in acetone. The suspension was stirred on a magnetic stirrer for 1 hour, and it was filtered on a cellulose nitrate filter with $0.45 \mu \mathrm{m}$ pore size. Then the bentonite was washed with acetone to wash the excess iron (III) ions and air dried at room temperature [26].

The La, Ce, Y, and Fe(III) concentrations of bentonite were determined by X-ray fluorescence analysis (XRF). Instrumental parameters were:

- $\mathrm{Si}(\mathrm{Li})$ detector with $20 \mathrm{~mm}^{2}$ surface and $3.5 \mathrm{~mm}$ evaporated layer (Atomki, Debrecen, Hungary),

- Canberra DSA 1000 digital spectrum analyzer (Canberra Industries, Meriden, CT 06450, USA),

- Canberra Genie 20003.0 spectroscopy software (Canberra Industries, Meriden, CT 06450, USA).

The $\mathrm{K}_{\alpha}$-lines of the lanthanide elements can be excited with $185 \mathrm{MBq} 241 \mathrm{Am}$ radioactive source [27].

\subsection{Kinetic studies of arsenite (III) sorption on modified bentonites}

The arsenite solution was prepared by dissolving $\mathrm{As}_{2} \mathrm{O}_{3}$ in water and adding $2 \mathrm{~g} \mathrm{NaOH}$ to the system. Sorption experiments of arsenite ion were carried out by batch technique. $100 \mathrm{mg}$ of cation exchanged bentonite was measured into beakers and $20 \mathrm{~cm}^{3}$ of $\mathrm{Na}_{3} \mathrm{AsO}_{3}$ solution $\left(5 \times 10^{-4} \mathrm{~mol} \mathrm{dm}^{-3}\right)$ was added. All samples were placed 
in a Bühler KS15A shaking bath at different temperatures $\left(1,25,35,40{ }^{\circ} \mathrm{C}\right)$ for 2-300 $\mathrm{min}$. After this time, the sorption samples were filtered through a $0.45 \mu \mathrm{m}$ pore size cellulose nitrate syringe filter and then the concentration in the solution $\left(c_{e}\right)$ was measured by inductively coupled plasma-optical emission spectrometry (ICP-OES) (SPS3 Agilent Technologies 5100). The pH of the solution was measured with a Clean $\mathrm{pH} 200 \mathrm{pH}$ meter and a Clean Cs1030 combined glass electrode. The amount of the sorbed arsenite (III) ions was determined by dividing the difference of the initial $\left(5 \times 10^{-4} \mathrm{~mol} \mathrm{dm}^{-3}\right)$ and the measured arsenite concentration (after the given time) with the mass of bentonite sorbent.

The kinetics of the arsenite (III) sorption was calculated using the software called Scientist. The first-order kinetic model Eq. (1) is:

$$
A=A_{e}(1-\exp (-k t))
$$

where $t$ is the time, $A$ is the arsenite (III) concentration in bentonite at any time, $A_{e}$ is the maximum amount of sorbed arsenite (III) on bentonite, $k$ is the first-order rate constant.

\subsection{Sorption isotherms of arsenite (III) sorption on La,}

\section{Ce, Y, Fe(III) modified bentonites}

A constant mass of solid (100 mg) was mixed with $20 \mathrm{~cm}^{3}$ solutions containing As(III) concentrations in the range of from 0.0005 to $0.005 \mathrm{~mol} \mathrm{dm}^{-3}$. Suspensions were shaken for 1 hour, so sorption equilibrium is reached. The additional steps were carried out as in Section 2.3. For X-ray diffraction (XRD) studies (Section 2.6), the solid phase of the sorption experiment with the initial concentration $5 \times 10^{-4} \mathrm{~mol} \mathrm{dm}^{-3}$ $\mathrm{Na}_{3} \mathrm{AsO}_{3}$ and at $25^{\circ} \mathrm{C}$ was prepared. After the sorption and filtration, the solid phase was dried at room temperature and powdered, then it was measured with XRD.

\subsubsection{Sorption of arsenic ions from groundwater}

La-, Ce-, Y-bentonites were used to sorb arsenic ions from groundwater samples. The groundwater samples were collected in Salonta (Romania). $100 \mathrm{mg}$ modified bentonite was put in $20 \mathrm{~cm}^{3}$ groundwater, than the samples were shaken for 1 hour at $25^{\circ} \mathrm{C}$. After that, the experiment was repeated without mixing, i.e., the samples consisting of $100 \mathrm{mg}$ bentonite and $20 \mathrm{~cm}^{3}$ groundwater, were left at room temperature for 1 day, and the arsenic concentrations $\left(c_{e}\right)$ were measured with ICP-OES, as in Section 2.4.

The basic properties as well as the concentration of dissolved ions of the groundwater are shown in Table 1 and Table 2 .
Table 1 Properties and heavy metal content of groundwater

\begin{tabular}{|c|c|}
\hline $\mathrm{pH}$ & 7.8 \\
\hline $\begin{array}{l}\text { conductivity } \\
\left(\mu \mathrm{S} \mathrm{cm}^{-1}\right)\end{array}$ & 340 \\
\hline $\begin{array}{l}\text { zinc } \\
\left(\mu \mathrm{g} \mathrm{L}^{-1}\right)\end{array}$ & $<20$ \\
\hline $\begin{array}{l}\text { cadmium } \\
\left(\mu \mathrm{g} \mathrm{L}^{-1}\right)\end{array}$ & $<0.05$ \\
\hline $\begin{array}{l}\text { chromium } \\
(\mathrm{III}+\mathrm{VI}) \\
\left(\mu \mathrm{g} \mathrm{L}^{-1}\right)\end{array}$ & $<0.5$ \\
\hline $\begin{array}{l}\text { copper } \\
\left(\mathrm{mol} \mathrm{dm}^{-3}\right)\end{array}$ & $1.45 \times 10^{-4}$ \\
\hline $\begin{array}{l}\text { iron } \\
\left.(\mathrm{mol} \mathrm{dm})^{-3}\right)\end{array}$ & $1.27 \times 10^{-4}$ \\
\hline $\begin{array}{l}\operatorname{arsenic} \\
\left(\mathrm{mol} \mathrm{dm}{ }^{-3}\right)\end{array}$ & $6.72 \times 10^{-7}$ \\
\hline
\end{tabular}

Table 2 The ion content of groundwater from Salonta (Romania)

\begin{tabular}{lrlr}
\hline & \multicolumn{1}{c}{$\begin{array}{c}\text { Anions } \\
\left(\mathrm{mol} \mathrm{dm}^{-3}\right)\end{array}$} & \multicolumn{2}{c}{$\begin{array}{c}\text { Cations } \\
\left(\mathrm{mol} \mathrm{dm}^{-3}\right)\end{array}$} \\
\hline Chloride & $2.04 \times 10^{-4}$ & Calcium & $7.14 \times 10^{-4}$ \\
Sulfate & $2.03 \times 10^{-4}$ & Magnesium & $1.50 \times 10^{-4}$ \\
Bicarbonate & $4.56 \times 10^{-3}$ & Potassium & $3.94 \times 10^{-5}$ \\
Fluoride & $1.05 \times 10^{-6}$ & Sodium & $4.06 \times 10^{-3}$ \\
Phosphate & $2.74 \times 10^{-6}$ & Lithium & $2.13 \times 10^{-5}$ \\
& & Ammonium & $9.98 \times 10^{-6}$ \\
\hline
\end{tabular}

\subsection{Desorption of arsenite (III) from} modified bentonites

These experiments were carried out to determine the desorbed quantity of arsenite (III) ion. Sorption samples were prepared as in the Section 2.4. $100 \mathrm{mg}$ bentonite containing $4.39 \times 10^{-5} \mathrm{~mol} \mathrm{~g}^{-1}$ arsenite (III) ion were added to $20 \mathrm{~cm}^{3}$ of distilled water. The suspensions were placed in a Bühler KS15A shaking bath at $25{ }^{\circ} \mathrm{C}$. After $1 \mathrm{~h}$, the samples were filtered through a $0.45 \mu \mathrm{m}$ pore size syringe filter and then $c_{e}$ was measured with ICP-OES. After filtration, the solid samples were dried at room temperature, powdered, and then were studied with XRD (Section 2.6).

\subsection{Determination of $d(001)$ basal spacing of montmorillonite in La, Ce, Y, Fe exchanged bentonites with XRD}

The d(001) basal spacing of REE-montmorillonite and that of after sorption and desorption, the preparation of which was written in Section 2.4 and 2.5, were determined with X-ray diffraction (XRD). A Philips PW1710 powder diffractometer equipped with a $\mathrm{CuK} \alpha$ source and a graphite 
monochromator (operating at $30 \mathrm{~mA}, 40 \mathrm{kV}$ ) was used. The scan rate was $2^{\circ} 2 \Theta / \mathrm{min}$.

\section{Results and discussion}

\subsection{La, Ce, Y, and Fe concentrations of bentonite measured by $\mathrm{X}$-ray fluorescence analysis}

REE and Fe concentrations measured by X-ray fluorescence analysis are summarized in Table 3 . As seen in Table 3, the ion exchange was successful. The REE and $\mathrm{Fe}(\mathrm{III})$ ion content in bentonite was higher than CEC values obtained by ammonium acetate method related to trivalent ions $\left(2.7 \times 10^{-4} \mathrm{~mol} \mathrm{~g}^{-1}\right)$. This was previously found both for La- and Ce-bentonites and Fe(III)-bentonite by Kovács et al. [27] and Kuzmann et al. [22, 24]. However, in the case of Y-bentonite, this phenomenon was firstly observed here.

Figs. 1-4 show the spectrum of $\mathrm{La}, \mathrm{Ce}, \mathrm{Y}$ and Fe modified bentonites. The red line was highligted by the Authors for better visibility.

In the case of $\mathrm{La}, \mathrm{Ce}, \mathrm{Y}$ and $\mathrm{Fe}$ the centroid of the highest peak area was $33.4 \mathrm{keV}, 34.5 \mathrm{keV}, 14.9 \mathrm{keV}$ and $6.4 \mathrm{keV}$, respectively, which are the $\mathrm{K}_{\alpha}-$ line of the elements. The result was analysed by external standard method. The intensity in count per second (cps) was determined by dividing the area of the La-peak with the time. The intensity was used to determine the $\mathrm{w} / \mathrm{w} \%$, from which the $\mathrm{mol} / \mathrm{g}$ amount shown in Table 3 was calculated.

\subsection{Kinetic studies of arsenite (III) sorption on modified bentonites}

Fig. 5 illustrates the sorption of arsenite (III) on lanthanum-modified bentonite. The sorption of arsenite (III) on the La-modified bentonite increases with time. At $1{ }^{\circ} \mathrm{C}$, only the equilibrium value was measured, because the kinetics was uncertain. This mechanism is very sensitive to temperature.

In this study the pseudo-first order sorption kinetic equation was used. The pseudo-second order sorption kinetic equation mentioned by Ho and McKay [28]

Table $3 \mathrm{La}, \mathrm{Ce}, \mathrm{Y}$, and Fe concentrations of bentonite measured by $\mathrm{X}$-ray fluorescence analysis (XRF)

\begin{tabular}{lcccc}
\hline & $\begin{array}{c}\text { La- } \\
\text { bentonite }\end{array}$ & $\begin{array}{c}\text { Ce- } \\
\text { bentonite }\end{array}$ & $\begin{array}{c}\text { Y- } \\
\text { bentonite }\end{array}$ & $\begin{array}{c}\text { Fe- } \\
\text { bentonite }\end{array}$ \\
\hline XRF $\left(\mathrm{mol} \mathrm{g}^{-1}\right)$ & $3.50 \times 10^{-4}$ & $\begin{array}{c}2.92 \times \\
10^{-4}\end{array}$ & $3.5 \times 10^{-4}$ & $4.85 \times 10^{-4}$ \\
$\begin{array}{l}\text { REE content } \\
\text { related to } \\
\text { CEC }(\%)\end{array}$ & 130 & 108 & 130 & 179 \\
\hline
\end{tabular}

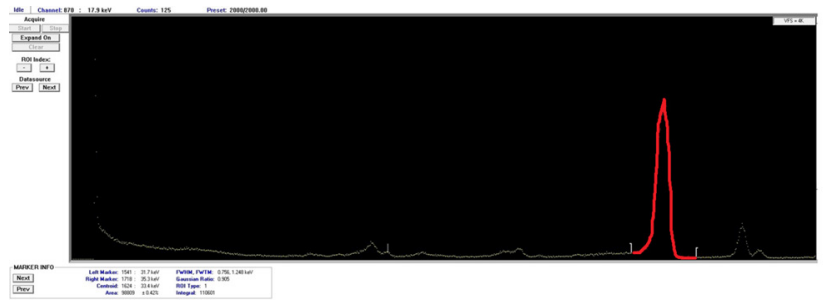

Fig. 1 The spectrum of La-bentonite with XRF

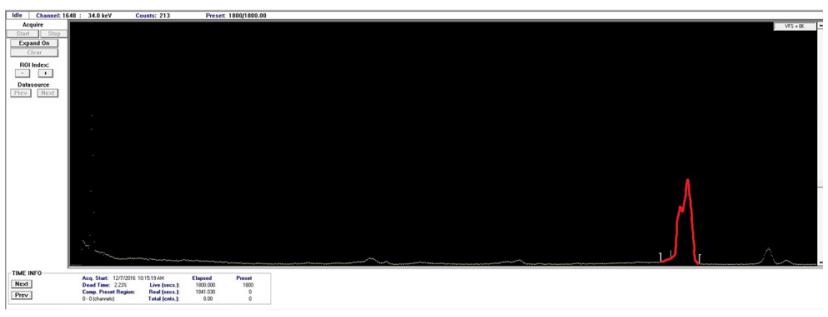

Fig. 2 The spectrum of Ce-bentonite with XRF

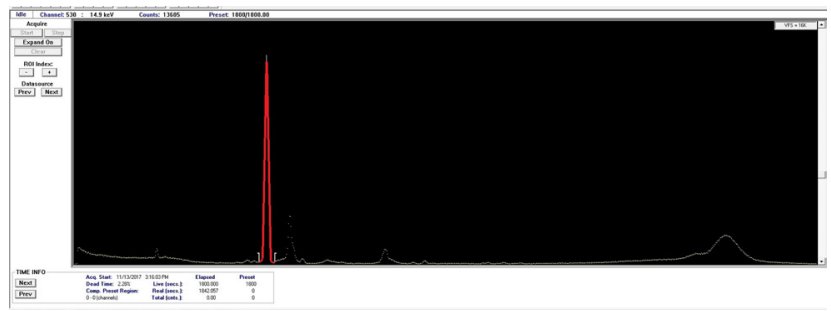

Fig. 3 The spectrum of Y-bentonite with XRF

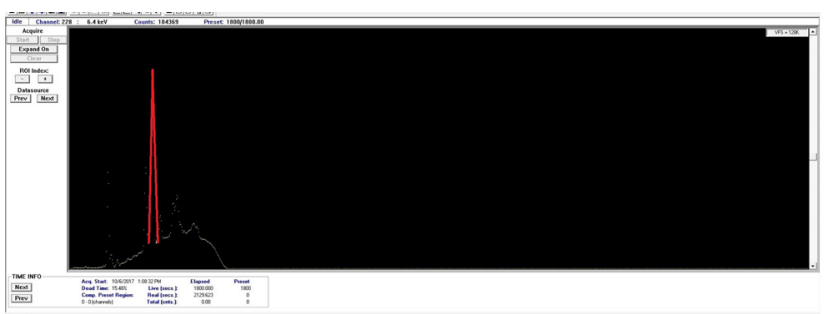

Fig. 4 The spectrum of Fe-bentonite with XRF

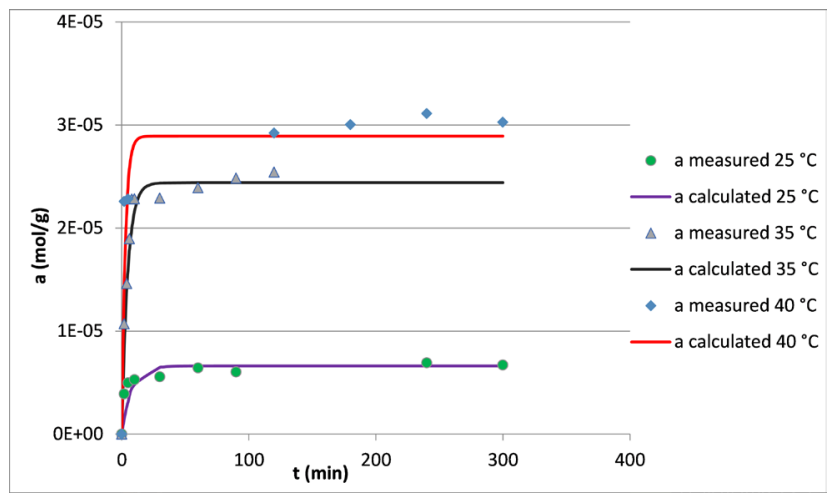

Fig. 5 Arsenite (III) sorption kinetics at $25^{\circ} \mathrm{C}, 35^{\circ} \mathrm{C}$ and $40{ }^{\circ} \mathrm{C}$ on lanthanum modified bentonite, $100 \mathrm{mg}$ bentonite, $20 \mathrm{~cm}^{3} 5 \times 10^{-4} \mathrm{~mol} \mathrm{dm}^{-3} \mathrm{Na}_{3} \mathrm{AsO}_{3}, \mathrm{pH} 7.0-8.43$ 
Table 4 Kinetic parameters at different temperatures on lanthanum modified bentonite ( $A_{e}$ and $k$ was calculated from the Eq. (1))

\begin{tabular}{lcc}
\hline \multicolumn{3}{c}{ La-bentonite } \\
\hline$A_{e}$ & $25^{\circ} \mathrm{C}$ \\
$k$ & $6.62 \times 10^{-6}$ & $\mathrm{~mol} \mathrm{~g}^{-1}$ \\
$\mathrm{pH}$ & 0.15 & $1 \mathrm{~min}^{-1}$ \\
$\mathbf{S D}$ & $7.0-8.03$ & \\
$\mathbf{R}^{2}$ & $\mathbf{1 . 2} \times \mathbf{1 0} 0^{-6}$ & \\
& $\mathbf{0 . 9 6 3 6}$ & \\
$A_{e}$ & $35^{\circ} \mathrm{C}$ & \\
$k$ & $2.44 \times 10^{-5}$ & $\mathrm{~mol} \mathrm{~g}^{-1}$ \\
$\mathrm{pH}$ & 0.26 & $1 \mathrm{~min}^{-1}$ \\
$\mathbf{S D}$ & $7.24-8.0$ & \\
$\mathbf{R}^{2}$ & $\mathbf{1 . 0 \times 1 0 ^ { - 6 }}$ & \\
& $\mathbf{0 . 9 9 8 0}$ & \\
$A_{e}$ & $40{ }^{\circ} \mathrm{C}$ & \\
$k$ & $2.92 \times 10^{-5}$ & $\mathrm{~mol} \mathrm{~g}^{-1}$ \\
$\mathrm{pH}$ & 0.44 & $1 \mathrm{~min}^{-1}$ \\
$\mathbf{S D}$ & $7.7-8.43$ & \\
$\mathbf{R}^{2}$ & $\mathbf{3 . 8} \times \mathbf{1 0}$ & \\
\hline & $\mathbf{0 . 9 8 2 2}$ & \\
\hline
\end{tabular}

was also tested, $\mathrm{R}^{2}$ values $\left(25{ }^{\circ} \mathrm{C}: 0.99 ; 35{ }^{\circ} \mathrm{C}\right.$ : 0.96 ; $\left.40{ }^{\circ} \mathrm{C}: 0.98\right)$ were better than the pseudo-first order sorption kinetic, but for the activation energy a negative value was obtained which is not a realistic value in reaction kinetics, because the rate is always increases as the temperature increases. Taking these into account in this study the pseudo-first order sorption kinetic equation was used. In the literature, first-order kinetics of As can also be observed for example Singh et al. [29].

The Arrhenius equation (Eq. (2)) was used to determine the activation energy $\left(E_{a}\right)$ of the arsenite (III) sorption. The $E_{a}$ was obtained by plotting the $\ln (k)$ versus $1 / T$.

$\ln k=\ln k_{0}-\frac{E_{a}}{R T}$

where $E_{a}$ is the activation energy $\left(\mathrm{kJ} \mathrm{mol}^{-1}\right), T$ is the temperature $(\mathrm{K}), R$ is the gas constant $(8.314 \mathrm{~J} / \mathrm{K} \mathrm{mol})$, and $k_{0}$ is Arrhenius constant.

The calculated $E_{a}$ value was $53 \mathrm{~kJ} \mathrm{~mol}^{-1}$, which is higher than the $E_{a}$ for phosphate sorption in our previous study [30], which was $22 \mathrm{~kJ} \mathrm{~mol}^{-1}$. Arsenite ion is bigger than phosphate ion, thus arsenite moves slower. It can be supposed that the rate determining step is the diffusion of arsenite ions in the interlayer of montmorillonite [29].

\subsection{Sorption isotherms of arsenite (III) ion sorption on La, Ce, Y, Fe modified bentonites}

As mentioned in Introduction, arsenic removal methods include precipitation, adsorption, oxidation, and ion exchange. When studying the sorption of arsenite anion on REE and iron (III)-bentonites, the oxidation and ion exchange is excluded. Adsorption and surface precipitation can be supposed.

Adsorption processes are frequently described by Langmuir isotherm model. This isotherm was originally derived for the adsorption of gas molecules on planar surfaces but frequently used in solid / solution systems. The Langmuir equation (Eq. (3)) can be expressed mathematically as follows:

$\frac{c_{e}}{a_{e}}=\frac{c_{e}}{z}+\frac{K}{z}$

where $a_{e}$ is the amount adsorbed at equilibrium ( $\left.\mathrm{mol} \mathrm{g}^{-1}\right), z$ is the maximum sorption capacity $\left(\mathrm{mol} \mathrm{g}^{-1}\right) c_{e}$ is the equilibrium solution concentration $\left(\mathrm{mol} \mathrm{dm}^{-3}\right)$, and $K$ is the solubility of the sorption complex $\left(\mathrm{mol} \mathrm{dm}^{-3}\right)$ [31].

In literature Freundlich and Tempkin isotherm models are also used, but in this study, Langmuir isotherm was used due to all four criterions were supposed to be fulfilled, as follows:

1. The adsorption takes place on the free sites of the adsorbent. The sorption of arsenite (III) ions takes place on free sites produced by the REE cations. It is supposed that in the case of natural calcium-bentonite, no sorption of arsenite ion can be observed.

2. One adsorption site can adsorb one molecule; monolayer coverage is maximum. The arsenite precipitates or adsorbs in the interlayer space on REE ions.

3. The adsorption sites have the same energy (homogeneous surface), no interaction between the adsorbed molecules. It means that the adsorption energy is independent of coverage. As a result of the equivalency of trivalent arsenite and REE ions, the REEarsenite sorption species are neutral, thus no electrostatic interaction occurs between particles.

4. There is adsorption equilibrium between the phases. Fig. 5 shows that the equilibrium is reached [32].

The isotherm of arsenite (III) sorption on Y-bentonite is illustrated in Fig. 6. For La-, Ce- and Fe-bentonites similar figures were plotted. The isotherm parameters were calculated from the slope of $c_{e} / a_{e}\left(\mathrm{~g} \mathrm{dm}^{-3}\right)$ versus $c_{e}\left(\mathrm{~mol} \mathrm{dm}{ }^{-3}\right)$ plots (Table 5). 


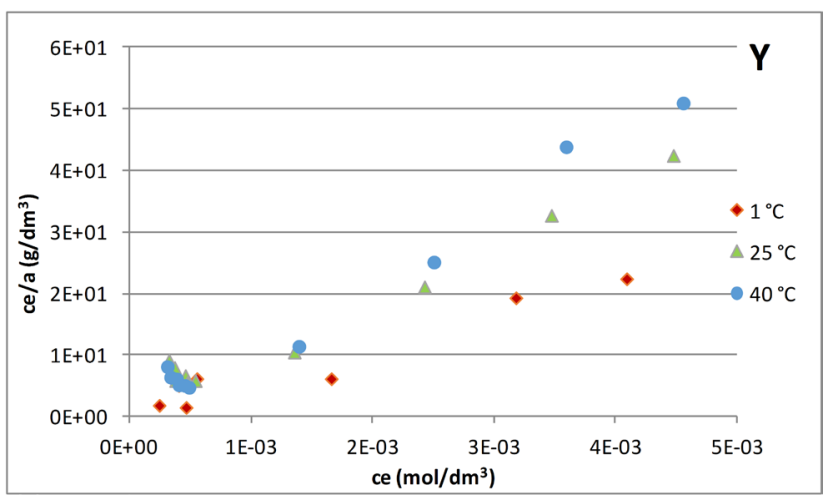

Fig. 6 Arsenite (III) sorption isotherms at $1{ }^{\circ} \mathrm{C}, 25^{\circ} \mathrm{C}$ and $40{ }^{\circ} \mathrm{C}$ on yttrium modified bentonite, $100 \mathrm{mg}$ bentonite, $20 \mathrm{~cm}^{3} \mathrm{Na}_{3} \mathrm{AsO}_{3}$, pH 5.92-10.25

Table 5 Isotherm parameters of arsenite (III) sorption on REE-bentonites

\begin{tabular}{|c|c|c|c|c|}
\hline \multicolumn{5}{|c|}{ La-bentonite } \\
\hline$T$ & $\begin{array}{c}\text { active sites } \\
\text { mol g }^{-1}\end{array}$ & SD & $\begin{array}{l}\text { solubility } \\
\text { mol dm }{ }^{-3}\end{array}$ & SD \\
\hline $1{ }^{\circ} \mathrm{C}$ & $1.15 \times 10^{-4}$ & $3.54 \times 10^{-5}$ & $1.43 \times 10^{-3}$ & $1.53 \times 10^{-4}$ \\
\hline $25^{\circ} \mathrm{C}$ & $1.10 \times 10^{-4}$ & $9.19 \times 10^{-5}$ & $1.20 \times 10^{-3}$ & $1.35 \times 10^{-4}$ \\
\hline $40^{\circ} \mathrm{C}$ & $1.30 \times 10^{-4}$ & $3.54 \times 10^{-5}$ & $8.50 \times 10^{-4}$ & $1.38 \times 10^{-4}$ \\
\hline \multicolumn{5}{|c|}{ Ce-bentonite } \\
\hline$T$ & $\begin{array}{c}\text { active sites } \\
\mathrm{mol} \mathrm{g}^{-1}\end{array}$ & SD & $\begin{array}{l}\text { solubility } \\
\mathrm{mol} \mathrm{dm}^{-3}\end{array}$ & SD \\
\hline $1{ }^{\circ} \mathrm{C}$ & $2.60 \times 10^{-4}$ & $4.76 \times 10^{-5}$ & $4.30 \times 10^{-3}$ & $1.28 \times 10^{-3}$ \\
\hline $25^{\circ} \mathrm{C}$ & $1.75 \times 10^{-4}$ & $9.83 \times 10^{-5}$ & $8.80 \times 10^{-4}$ & $1.84 \times 10^{-5}$ \\
\hline $40{ }^{\circ} \mathrm{C}$ & $1.60 \times 10^{-4}$ & $5.52 \times 10^{-5}$ & $4.80 \times 10^{-4}$ & $1.58 \times 10^{-4}$ \\
\hline \multicolumn{5}{|c|}{ Y-bentonite } \\
\hline$T$ & $\begin{array}{c}\text { active sites } \\
\text { mol g }^{-1}\end{array}$ & SD & $\begin{array}{l}\text { solubility } \\
\text { mol dm }{ }^{-3}\end{array}$ & SD \\
\hline $1{ }^{\circ} \mathrm{C}$ & $2.60 \times 10^{-4}$ & $5.70 \times 10^{-5}$ & $3.70 \times 10^{-3}$ & $3.71 \times 10^{-4}$ \\
\hline $25^{\circ} \mathrm{C}$ & $1.15 \times 10^{-4}$ & $3.54 \times 10^{-5}$ & $3.60 \times 10^{-4}$ & $6.36 \times 10^{-5}$ \\
\hline $40{ }^{\circ} \mathrm{C}$ & $1.00 \times 10^{-4}$ & $1.77 \times 10^{-5}$ & $1.60 \times 10^{-4}$ & $1.34 \times 10^{-5}$ \\
\hline
\end{tabular}

As seen in Table 5, La-, Ce- and Y-bentonites can bind similar amount of arsenite (III) ions under the same experimental conditions. The solubilities of the sorption complex (rare earth ion-arsenite-bentonite) decreased with the increasing of temperature. This suggests an exothermic surface sorption process.

The tendencies of solubilities of the complex and active sites versus temperature show the exothermic arsenite sorption reaction. In the absence of literature data for the solubilites of metal - arsenite (III) compounds, the solubility of REE-arsenite-bentonites complex was compared to the solubilities of REE-phosphate-bentonites complexes in our previous study [30]. It can be found that the solubility of the
REE-phosphate-bentonite complex was two orders of magnitude smaller than that of the arsenite complex.

Fe-bentonite cannot bind significant amount of arsenite (III) ions. For Fe-bentonite the error of the results has a large deviation. At $25{ }^{\circ} \mathrm{C}$, the sorbed amount of arsenite (III) on Fe-bentonite is about $5 \%$ sorbed on REEbentonites. Thus, the values obtained in the case of Fe-bentonite will not be discussed.

In Table 5, the maximum sorption capacity was listed in $\mathrm{mol} \mathrm{g}^{-1}$. To compare our results with literature data, these values are given in $\mathrm{mg} \mathrm{g}^{-1}$, too. Accordingly, the maximum sorption capacities of La-, Ce-, Y-bentonites for As(III) at $25^{\circ} \mathrm{C}$ was $8.24 \mathrm{mg} \mathrm{g}^{-1}, 13.11 \mathrm{mg} \mathrm{g}^{-1}$, and $8.62 \mathrm{mg} \mathrm{g}^{-1}$, respectively. Lower results were obtained for lanthanum-exchanged zeolite $\left(2.80 \times 10^{-3} \mathrm{mg} \mathrm{g}^{-1} ; 2.54 \times 10^{-3} \mathrm{mg} \mathrm{g}^{-1}\right)$ [31]. In addition, the maximum sorption capacity of the cerium-loaded cation exchange resin, which was prepared by impregnating cerium into the cation exchange resin, was also lower, $2.53 \mathrm{mg} \mathrm{g}^{-1}$ [34]. Zongliang et al. [34] observed that the value of maximum adsorption capacity for As(III) on cerium-loaded resin decreased with the increasing of temperature which showed the exothermic nature of the sorption process. This is in a good agreement with our findings, that is the active sites in Table 5 decrease as the temperature increases.

\subsubsection{Sorption of arsenite ions from groundwater}

We wanted to see how REE-bentonites reduce arsenic content in natural water that has other ions than arsenite. Therefore, an experiment was carried out under the same conditions as previous sorption experiments (Section 2.4). Modified ( $\mathrm{La}, \mathrm{Ce}, \mathrm{Y}$ ) bentonites were used to remove arsenic from groundwater. The initial arsenic concentration of groundwater was $6.72 \times 10^{-7} \mathrm{~mol} \mathrm{dm}^{-3}$ (Table 1). After sorption with each modified bentonite, the arsenic concentrations decreased below the detection limit ICPOES $\left(3.4 \times 10^{-8} \mathrm{~mol} \mathrm{dm}^{-3}(4 \mu \mathrm{g} / \mathrm{l})\right)$. This means that the modified bentonites can sorb arsenic ions from water and can reduce the arsenic concentration in water below the limit determined by the World Health Organization, which is $1.33 \times 10^{-7} \mathrm{~mol} \mathrm{dm}^{-3}\left(10 \mu \mathrm{g}^{-1}\right)$.

\subsection{Desorption experiments of arsenite (III) on modified bentonites}

It is important to regenerate the spent adsorbent and to reuse it in order to the adsorption process be more efficient and more economical. Several studies dealt with the regeneration of clays using $\mathrm{NaCl}[35], \mathrm{HCl}[36,37]$, 
$\mathrm{NH}_{4} \mathrm{Cl}$ [38] and phosphate [39]. In this study, hence the regeneration was tried by desorption after a sorption experiment where the rare earth (La-)bentonite containing $4.39 \times 10^{-5} \mathrm{~mol} \mathrm{~g}^{-1}$ arsenic. Under the conditions of desorption (Section 2.5), $9.78 \times 10^{-6} \mathrm{~mol} \mathrm{~g}^{-1}$ was dissolved, $1.22 \mathrm{x}$ $10^{-5} \mathrm{~mol} \mathrm{~g}^{-1}$ remained on bentonite, this means the sorbed amount of arsenite (III) was $4.39 \times 10^{-5} \mathrm{~mol} \mathrm{~g}^{-1}$ and after desorption it was $2.43 \times 10^{-5} \mathrm{~mol} \mathrm{~g}^{-1}$. The dissolved amount of arsenite (III) was $44.6 \%$. Therefore, the sorbent can be regenerated. Examination of enhancement and re-use of the sorbents will be carried out.

\subsection{Results of d(001) basal spacing of montmorillonite of La, Ce, Y, Fe exchanged bentonites with XRD}

Since it was previously assumed that the REE ions in the interlayer space of montmorillonite bind the arsenite ions, it was examined how this can affect the structure, a good indicator of which is the $\mathrm{d}(001)$ basal spacing determined by XRD. Table 6, Table 7, and Fig. 7 show the results of XRD used to determine the $\mathrm{d}(001)$ basal spacing of REEmontmorillonite and that of after sorption and desorption of arsenite. Desorption experiments were carried out only in the case of La-bentonite.

Table 6 Results of d(001) basal spacing of montmorillonite in $\mathrm{La}, \mathrm{Ce}$ exchanged bentonites with XRD

\begin{tabular}{lccc}
\hline & Ca-bentonite & La-bentonite & Ce-bentonite \\
\hline $\begin{array}{l}\mathrm{d}(001) \text { basal spacing } \\
(\mathrm{nm})\end{array}$ & 1.4769 & 1.5159 & 1.4998 \\
$\mathrm{~d}(001)$ basal spacing & & \\
$\begin{array}{l}\text { after sorption of } \\
\text { arsenite (nm) }\end{array}$ & 1.3916 & 1.3816 \\
$\begin{array}{l}\text { arsenite content after } \\
\text { sorption (mol g-1) }\end{array}$ & $4.39 \times 10^{-5}$ & $5.37 \times 10^{-5}$ \\
$\begin{array}{l}\mathrm{d}(001) \text { basal spacing } \\
\text { after desorption of } \\
\text { arsenite (nm) }\end{array}$ & & \\
$\begin{array}{l}\text { arsenite content after } \\
\text { desorption (mol g }\end{array}$ & 1.4769 & \\
\hline
\end{tabular}

Table 7 Results of d(001) basal spacing of montmorillonite in Y, Fe exchanged bentonites with XRD

\begin{tabular}{lccc}
\hline & Ca-bentonite & Y-bentonite & Fe-bentonite \\
\hline $\begin{array}{l}\mathrm{d}(001) \text { basal spacing } \\
(\mathrm{nm})\end{array}$ & 1.4769 & 1.4769 & 1.3431 \\
$\mathrm{~d}(001)$ basal spacing & & \\
$\begin{array}{l}\text { after sorption of } \\
\text { arsenite (nm) }\end{array}$ & 1.412 & 1.2893 \\
$\begin{array}{l}\text { arsenite content after } \\
\text { sorption (mol g-1) }\end{array}$ & $5.71 \times 10^{-5}$ & $2.97 \times 10^{-6}$ \\
\hline
\end{tabular}

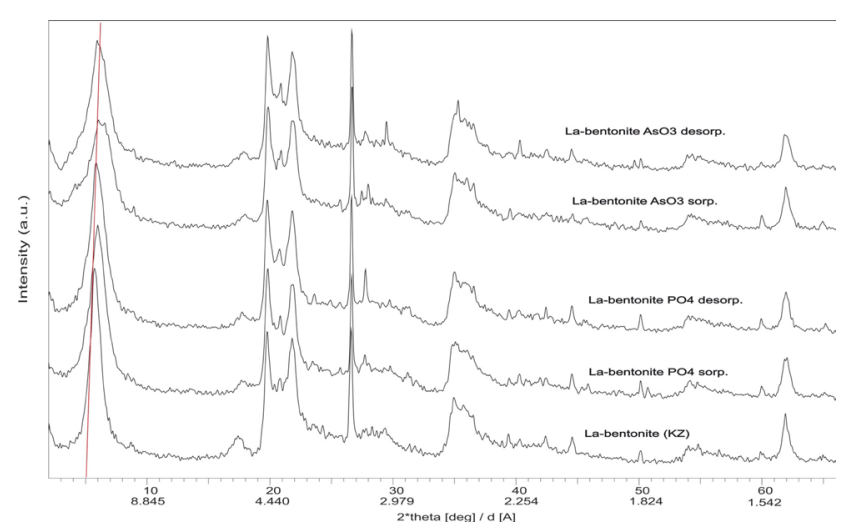

Fig. 7 XRD spectrum of La-bentonite and that of after sorption and desorption of arsenite and phosphate, the unit of $y$ axis is arbitrary unit (a.u.)

The $d(001)$ basal spacing of the original Ca-montmorillonite is $1.4769 \mathrm{~nm}$ showing that in the interlayer space there are mostly bivalent calcium ions. As a result with cation exchange with REE ions, an increase in $\mathrm{d}(001)$ basal spacing of montmorillonite is observed proving the ion exchange of trivalent REE cations. As mentioned in Section 3.1, the XRF measurements also show the exchange of REE ions.

After the sorption of arsenite ions, the $\mathrm{d}(001)$ basal spacing decreases suggesting that the size of the interlayer space decreases, the aluminosilicate layers tend to approach each other. This decrease of $\mathrm{d}(001)$ basal spacing may be interpreted by the precipitation reaction of REE cation and arsenite anion in the interlayer space. As a result, the REE cations originally neutralizing the layer charge and reacting with the arsenite ions cannot neutralize the layer charge any more. The negative layer charge, however, must be neutralized by the sodium ions added to the system as the co-ion of arsenite ion, and maybe hydrogen ions. As a result, monovalent sodium ions are in the interlayer space. It is wellknown that the $\mathrm{d}(001)$ basal spacing of monovalent montmorillonite is less than that of bivalent montmorillonite.

This effect can explain the decrease of the basal spacing. After desorption, an increase in $\mathrm{d}(001)$ basal spacing was observed again. This increase, however, is less than of the $d(001)$ basal spacing of La-bentonite before the sorption of arsenite ions and at the same time about $55 \%$ $\left(2.43 \times 10^{-5} \mathrm{~mol} \mathrm{~g}^{-1}\right)$ of arsenite ion remains on bentonite. The solubilities of the sorption complex (Table 5), the significant desorption of arsenite by a simple leaching, as well as the changes in the $\mathrm{d}(001)$ basal spacing of montmorillonite show that the solubility of montmorillonite-REE-arsenite sorption complex may be rather great. Unfortunately, 
we have not found solubility data on REE arsenites, so we cannot compare our result with literature data.

After the sorption of phosphate ions (Fig. 7), the same phenomenon occurs and the cause of the wider peak during arsenite sorption is that arsenite ion is bigger than phosphate ion.

\section{Conclusion}

Four modified bentonites ( $\mathrm{La}(\mathrm{III}), \mathrm{Ce}(\mathrm{III}), \mathrm{Y}(\mathrm{III})$, and $\mathrm{Fe}(\mathrm{III})$ ) were prepared for sorption of arsenite ion from aqueous solution. La-, Ce- and Y-bentonites could sorbed arsenite (III) ions, however, iron (III)-bentonite could not.

In equilibrium, the relation between the sorbed and dissolved arsenite concentration can be described by Langmuir isotherm. The experiments at different temperature suggest an exothermic surface precipitation process. After the sorption of arsenit ion on REE exchanged bentonites, the $\mathrm{d}(001)$ basal spacing of montmorillonite was decreased

\section{References}

[1] Welch, A. H., Lico, M. S., Hughes, J. L. "Arsenic in Ground Water of the Western United States", Groundwater, 26(3), pp. 333-347, 1988.

https://doi.org/10.1111/j.1745-6584.1988.tb00397.x

[2] Kaltreider, R. C., Davis, A. M., Lariviere, J. P., Hamilton, J. W. "Arsenic Alters the Function of the Glucocorticoid Receptor as a Transcription Factor", Environmental Health Perspectives, 109(3), pp. 245-251, 2001.

[3] World Health Organization. "Preventing Disease through Healthy Environments, Exposure to Lead: a Major Public Health Concern", WHO, Geneva, Switzerland, 2010.

[4] Meacher, D. M., Menzel, D. B., Dillencourt, M. D., Bic L. F., Schoof, R. A., Yost, L. J., Eickhoff, J. C., Farr, C. H. "Estimation of Multimedia Inorganic Arsenic Intake in the U.S. Population", Human and Ecological Risk Assessment, 8(7), pp. 1697-1721, 2002.

[5] Jain, C. K., Ali, I. "Arsenic: occurrence, toxicity and speciation techniques", Water Research, 34(17), pp. 4304-4312, 2000 https://doi.org/10.1016/S0043-1354(00)00182-2

[6] Ungureanu, G., Santos, S., Boaventura, R., Botelho, C. "Arsenic and antimony in water and wastewater: Overview of removal techniques with special reference to latest advances in adsorption", Journal of Environmental Management, 151, pp. 326-342, 2015. https://doi.org/10.1016/j.jenvman.2014.12.051

[7] Basu, T., Ghosh, U. C. "Arsenic(III) removal performances in the absence / presence of groundwater occurring ions of agglomerated $\mathrm{Fe}(\mathrm{III})-\mathrm{Al}(\mathrm{III})$ mixed oxide nanoparticles", Journal of Industrial and Engineering Chemistry, 17(5-6), pp. 834-844, 2011. https://doi.org/10.1016/j.jiec.2011.09.002

[8] Goh, K.-H., Lim, T.-T., Dong, Z. "Enhanced Arsenic Removal by Hydrothermally Treated Nanocrystalline Mg / Al Layered Double Hydroxide with Nitrate Intercalation", Environmental Science \& Technology, 43(7), pp. 2537-2543, 2009. https://doi.org/10.1021/es802811n showing the sorption of arsenite ions in the interlayer space. After desorption of arsenite ions by a simple washing, an increase in $\mathrm{d}(001)$ was observed again. Desorption experiments show that the significant portion of the sorbed arsenite ions can be leached from rare earth-bentonites, thus the regeneration of the sorbent can be solved.

Arsenite ions could be sorbed by the modified bentonites from natural water containing the usual components of groundwaters.

\section{Acknowledgement}

The authors thank Peter Konya for the XDR measurements.

The project presented in this article is supported by the EU and co-financed by the European Regional Development Fund under the project GINOP-2.3.2-15-2016-00008.

The work was supported by the Hungarian National Research, Development, and Innovation Office (NKFIH K 120265).

[9] Gupta, K., Maity, A., Ghosh, U. C. "Manganese associated nanoparticles agglomerate of iron(III) oxide: Synthesis, characterization and arsenic(III) sorption behavior with mechanism", Journal of Hazardous Materials, 184(1-3), pp. 832-842, 2010. https://doi.org/10.1016/j.jhazmat.2010.08.117

[10] Dixit, S., Hering, J. G. "Comparison of Arsenic(V) and Arsenic(III) Sorption onto Iron Oxide Minerals: Implications for Arsenic Mobility", Environmental Science \& Technology, 37(18), pp. 4182-4189, 2003. https://doi.org/10.1021/es030309t

[11] Luther, S., Borgfeld, N., Kim, J., Parsons, J. G. "Removal of arsenic from aqueous solution: A study of the effects of $\mathrm{pH}$ and interfering ions using iron oxide nanomaterials", Microchemical Journal, 101, pp. 30-36, 2012. https://doi.org/10.1016/j.microc.2011.10.001

[12] Zhu, J., Pigna, M., Cozzolino, V., Caporale, A. G., Violante, A. "Sorption of arsenite and arsenate on ferrihydrite: Effect of organic and inorganic ligands", Journal of Hazardous Materials, 189(1-2), pp. 564-571, 2011 https://doi.org/10.1016/j.jhazmat.2011.02.071

[13] Kim, Y., Kim, C., Choi, I., Rengaraj, S., Yi, J. "Arsenic Removal Using Mesoporous Alumina Prepared via a Templating Method", Environmental Science \& Technology, 38(3), pp. 924-931, 2004. https://doi.org/10.1021/es0346431

[14] Li, W., Harrington, R., Tang, Y., Kubicki, J. D., Aryanpour, M., Reeder, R. J., Parise, J. B., Phillips, B. L., "Differential Pair Distribution Function Study of the Structure of Arsenate Adsorbed on Nanocrystalline $\gamma$-Alumina", Environmental Science \& Technology, 45(22), pp. 9687-9692, 2011. https://doi.org/10.1021/es200750b

[15] Lin, T.-F., Wu, J.-K. "Adsorption of Arsenite and Arsenate within Activated Alumina Grains: Equilibrium and Kinetics", Water Research, 35(8), pp. 2049-2057, 2001. https://doi.org/10.1016/S0043-1354(00)00467-X 
[16] Gu, Z., Fang, J., Deng, B. "Preparation and Evaluation of GAC-Based Iron-Containing Adsorbents for Arsenic Removal", Environmental Science \& Technology, 39(10), pp. 3833-3843, 2005. https://doi.org/10.1021/es048179r

[17] Luengo, C., Puccia, V., Avena, M. "Arsenate adsorption and desorption kinetics on a Fe(III)-modified montmorillonite", Journal of Hazardous Materials, 186(2-3), pp. 1713-1719, 2011. https://doi.org/10.1016/j.jhazmat.2010.12.074

[18] Hu, B., Luo, H. "Adsorption of hexavalent chromium onto montmorillonite modified with hydroxyaluminum and cetyltrimethylammonium bromide", Applied Surface Scence, 257(3), pp. 769775, 2010.

https://doi.org/10.1016/j.apsusc.2010.07.062

[19] de Paiva, L. B., Morales, A. R, Valenzuela Díaz, F. R. "Organoclays: Properties, preparation and applications", Applied Clay Science, 42(1-2), pp. 8-24, 2008.

https://doi.org/10.1016/j.clay.2008.02.006

[20] Stathi, P., Litina, K., Gournis, D., Giannopoulos, T. S., Deligiannakis, Y. "Physicochemical study of novel organoclays as heavy metal ion adsorbents for environmental remediation", Journal of Colloid Interface Science, 316(2), pp. 298-309, 2007. https://doi.org/10.1016/j.jcis.2007.07.078

[21] Douglas, G. B. United States Patent 6350383 B1: Remediation Material and Remediation Process for Sediments, Assignee: Commonwealth Scientific and Industrial Research Organisation, Australian Capitol Territory, Australia, 2002.

[22] Kuzmann, E., Singh, L. H., Garg, V. K., de Oliveira, A. C., Kovács, E. M., Molnár, Á. M., Homonnay, Z., Kónya, P., Nagy, N. M., Kónya, J. "Mössbauer study of the effect of rare earth substitution into montmorillonite", Hyperfine Interactions, 237(2), pp. 1-8, 2016.

https://doi.org/10.1007/s10751-016-1225-5

[23] Richards, L. A. (ed.) "Diagnosis and Improvement of Saline and Alkali Soils", United States Department of Agriculture, Washington, USA, 1957.

[24] Kuzmann, E,. Garg, V. K., Singh, H., de Oliveira, A. C., Pati, S. S., Homonnay, Z., Rudolf, M., Molnár, Á. M., Kovács, E. M., Baranyai, E., Kubuki, S., Nagy, N. M., Kónya, J., "Mössbauer study of $\mathrm{pH}$ dependence of iron-intercalation in montmorillonite", Hyperfine Interactions, 237(106), pp. 1-6, 2016. https://doi.org/10.1007/s10751-016-1314-5

[25] Komlósi, A., Kuzmann, E., Nagy, N. M., Homonnay, Z., Kubuki, S., Kónya, J. "Incorporation of $\mathrm{Fe}$ in the interlayer of Na-bentonite via treatment with $\mathrm{FeCl}_{3}$ in acetone", Clays and Clay Minerals, 55(1), pp. 89-95, 2007. https://doi.org/10.1346/CCMN.2007.0550107

[26] Li, T.-S., Zhang, Z.-H., Gao, Y.-J. "A Rapid Preparation of Acylals of Aldehydes Catalysed by $\mathrm{Fe}^{3+}$ - Montmorillonite", Synthetic Communications, 28(24), pp. 4665-4671, 1998. https://doi.org/10.1080/00397919808004531

[27] Kovács, E. M., Erdélyiné Baradács, E., Kónya, P., Kovács-Pálffy, P., Harangi, S., Kuzmann, E., Kónya J., Nagy, N. M. "Preparation and structure's analyses of lanthanide (Ln)-exchanged bentonites", Colloids and Surfaces A: Physicochemica and Engineering Aspects, 522, pp. 287-294, 2017.

https://doi.org/10.1016/j.colsurfa.2017.02.085
[28] Ho, Y. S., McKay, G. "Pseudo-second order model for sorption processes", Process Biochemistry, 34(5), pp. 451-465, 1999. https://doi.org/10.1016/S0032-9592(98)00112-5

[29] Singh, D. B., Prasad, G., Rupainwar, D. C. "Adsorption technique for the treatment of $\mathrm{As}(\mathrm{V})$-rich effluents", Colloids and Surfaces A: Physicochemical and Engineering Aspects, 111(1-2), pp. 49-56, 1996. https://doi.org/10.1016/0927-7757(95)03468-4

[30] Buzetzky, D., Nagy, N. M., Kónya, J. "Use of La-, Ce-, Y-, Fe- bentonites for Removing Phosphate Ions from Aqueous Media", Periodica Polytechnica Chemical Engineering, 61(1), pp. 27-32, 2017.

https://doi.org/10.3311/PPch.9871

[31] Nagy, N. M., Kónya, J. "Interfacial Chemistry of Rocks and Soils", 1st ed., CRC Press, Taylor and Francis Group, New York, USA, 2009.

[32] Fowler, R. H. "A Statistical Derivation of the Langmuir's Adsorption Isotherm", Mathematical Proceedings of the Cambridge Philosophical Society, 31(2), pp. 260-264, 1935. https://doi.org/10.1017/S0305004100013359

[33] Haron, M. J., Masdan, S. A., Hussein, M. Z., Zainal, Z., Kassim, A. "Kinetics and thermodynamic for sorption of arsenate by Lanthanum-exchanged zeolite", Malaysian Journal of Analytical Sciences, 11(1), pp. 219-228, 2007.

[34] He, Z., Tian, S., Ning, P. "Adsorption of arsenate and arsenite from aqueous solutions by cerium-loaded cation exchange resin", Journal of Rare Earths, 30(6), pp. 563-572, 2012. https://doi.org/10.1016/S1002-0721(12)60092-1

[35] Ramesh, A., Mohan, K. R., Seshaiah, K., Chowdary, N. V. "Removal of beryllium from aqueous solutions by zeolite $4 \mathrm{~A}$ and bentonite", Separation Science and Technology, 37(5), pp. 1123-1134, 2002. https://doi.org/10.1081/SS-120002245

[36] Manohar, D. M., Noeline, B. F., Anirudhan, T. S. "Removal of Vanadium(IV) from Aqueous Solutions by Adsorption Process with Aluminum-Pillared Bentonite", Industrial \& Engineering Chemistry Research, 44(17), pp. 6676-6684, 2005. https://doi.org/10.1021/ie0490841

[37] Lenoble, V., Bouras, O., Deluchat, V., Serpaud, B., Bollinger, J.-C. "Arsenic Adsorption onto Pillared Clays and Iron Oxides", Journal of Colloid and Interface Science, 255(1), pp. 52-58, 2002. https://doi.org/10.1006/jcis.2002.8646

[38] Adebowale, K. O., Unuabonah, I. E., Olu-Owolabi, B. I. "Adsorption of some heavy metal ions on sulfate- and phosphate-modified kaolin", Applied Clay Science, 29(2), pp. 145-148, 2005. https://doi.org/10.1016/j.clay.2004.10.003

[39] Manning, B. A., Goldberg, S. "Adsorption and Stability of Arsenic(III) at the Clay Mineral-Water Interface", Environmental Science \& Technology, 31(7), pp. 2005-2011, 1997. https://doi.org/10.1021/es9608104 